\title{
A review on the applications of programmable logic controllers (PLCs)
}

\author{
Ephrem Ryan Alphonsus ${ }^{a}$, Mohammad Omar Abdullah ${ }^{\text {b,* }}$ \\ a International College of Advanced Technology Sarawak (iCATs), Jalan Canna, Off Jalan Wan Alwi, Tabuan Jaya, 93350 Kuching, Sarawak, Malaysia \\ b Department of Chemical Engineering and Energy Sustainability, Faculty of Engineering, University Malaysia Sarawak (UNIMAS), 93350 Kuching, Sarawak, \\ Malaysia
}

\section{A R T I C L E I N F O}

\section{Article history:}

Received 18 May 2014

Received in revised form

6 January 2016

Accepted 7 January 2016

Available online 27 February 2016

Keywords:

PLC

Energy systems

Industrial control

Monitoring

\begin{abstract}
A B S T R A C T
As the need of automation increases significantly, a control system needs to be easily programmable, flexible, reliable, robust and cost effective. In this paper a review on the application of programmable logic controller (PLC) in our current market is discussed. Investigations on the applications of PLCs in energy research, engineering studies, industrial control applications and monitoring of plants are reviewed in this paper. PLCs do have its own limitations, but findings indicate that PLCs have more advantages than limitations. This paper concludes that PLCs can be used for any applications whether it is of simple or complicated control system.
\end{abstract}

(c) 2016 Elsevier Ltd. All rights reserved.

\section{Contents}

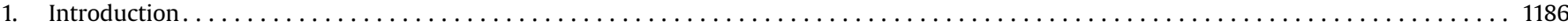

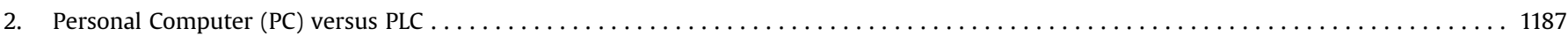

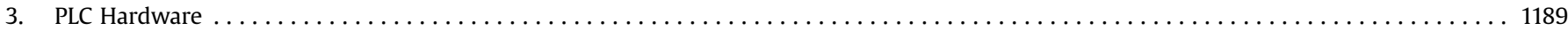

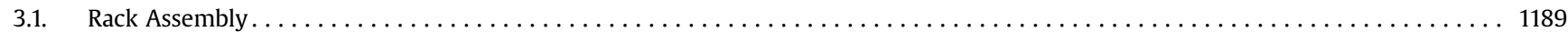

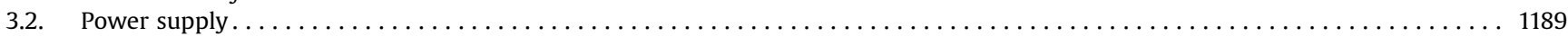

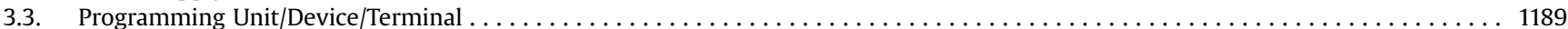

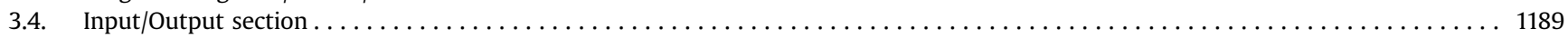

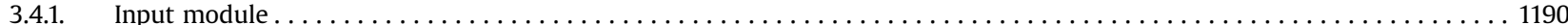

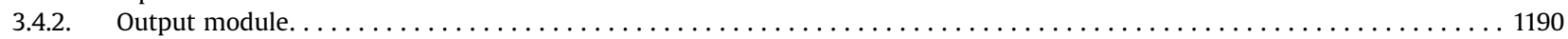

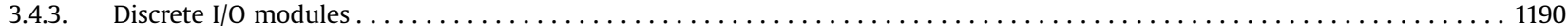

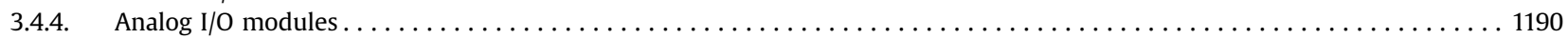

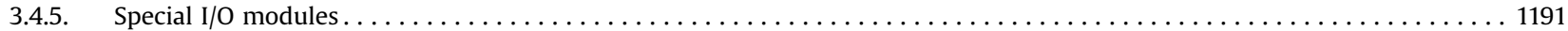

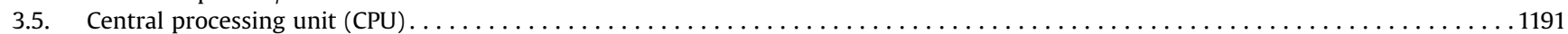

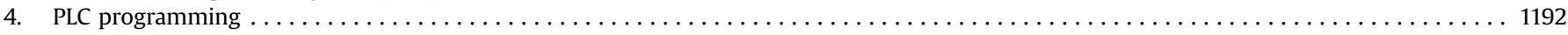

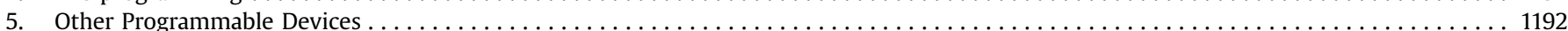

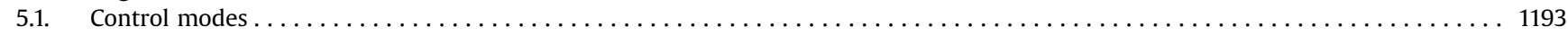

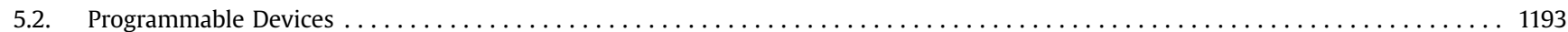

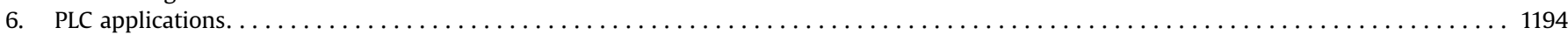

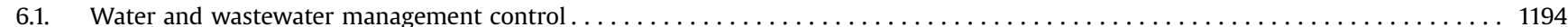

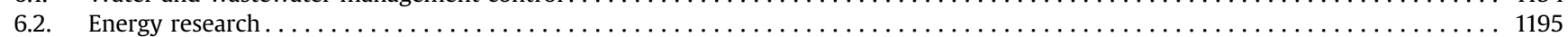

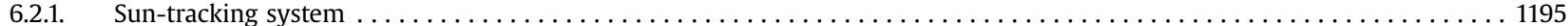

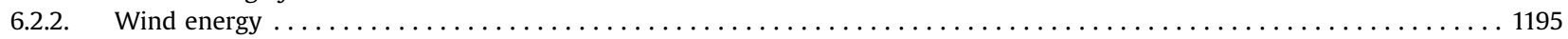

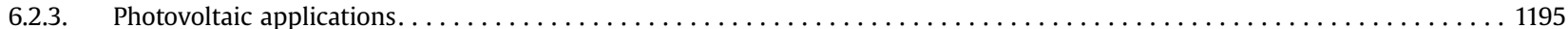

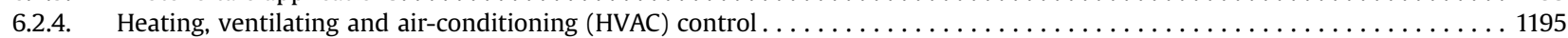

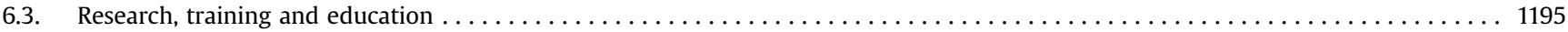

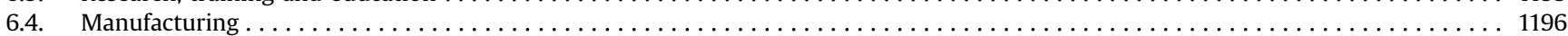

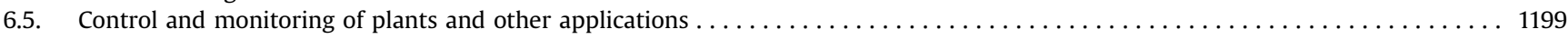

\footnotetext{
*Corresponding author. Tel.: +60 82 583280; fax: +082 583409.
} 